\title{
Brand identity development
}

\author{
Marina Ianenko, ${ }^{1, *}$, Mikhail Stepanov ${ }^{2}$, and Liubov Mironova ${ }^{2}$ \\ ${ }^{1}$ Peter the Great St.Petersburg Polytechnic University, 195251, 29 Polytekhnicheskaya str., Saint- \\ Petersburg, Russia \\ ${ }^{2}$ St. Petersburg State University of Industrial Technologies and Design, 191186, 18 Bolshaya \\ Morskaya str., Saint-Petersburg, Russia
}

\begin{abstract}
The paper studied the concept of "brand identity" as a planned brand image that defines the direction for all marketing activities of a company. The authors developed an algorithm for constructing a system of characteristic features of the brand strategy, harmoniously combined with the corporate and business strategy which includes the market situation analysis, an analysis of economic conditions and activities of the organization, analysis of marketing affords, analysis of the marketing strategy, the brand strategy selection, the brand positioning choice, brand identity development. Based on the well-established brand identity models such as The Brand Identity System (D.A. Aaker, USA), The Brand Identity Prism (J.-N. Kapferer France), L. De Chernatoni's model (UK), 4D Branding (T. Gad, Sweden), The Brand Wheel (Bates Worldwide, USA), The Brand Platform (Young \& Rubicam, USA) the authors have discussed the current approaches to the brand identity creation depending on which market (customer or B2B) a firm participates in perform and its capacity to serve the interests of both corporate and individual customers. The proposed approaches are needed for successful brand management.
\end{abstract}

\section{Introduction}

The basic concept of branding is the brand identity - an idea of what a brand should be, what it aspires to. Identity is a planned image of a brand defining directions for all of the firm's marketing activities.

The problems of brand identity development have been studied in the works of D. A. Aaker (USA), J.-N. Kapferer (France), L. De Chernatoni (UK), T. Gad (Sweden), and the others [1]. Recently, the special scientific interest was attracted to the issue of creating corporate identity in relation to business markets. Among the scholars covering this scientific problem, we can distinguish S. Fournier, M. Breazeale, J. Avery [2], C. Viot, [3], M. Urde, [4] R.R. Gehani [5].

What does the term "brand identity" mean? Researchers interpret this notion in different ways. The concept of brand identity was first proposed by J.-N. Kapferer in 1986 [6].

Then, in 1995, it became the main theme of D. Aaker's book, Creating Strong Brands [7].Today, the concept of brand identity is used by many experts such as: G. L. Bagiev, T.

\footnotetext{
*Corresponding author: yanenko_57@mail.ru
} 
Ambler, W. Pförtsch[8], D. Aaker, V.N. Domnin[6], J.J. Lambin, A. Wheeler, and the others [1].

D. Aaker gives the following interpretation of the term: "Brand identity is a unique set of associations that the brand's developer seeks to create or maintain. These associations represent the value of the brand and the promises that are given to consumers by members of the organization." [9] J.-N. Kapferer points to the functions of differentiation and influence on consumers. He writes that brand identity "specifies the facets of brands' uniqueness and value." L. de Chernatoni highlights the function of differentiation. In his opinion, brand identity is "the character, goals and values that represent the unique differentiation of a brand".

However, it should be noted that the scholars and practitioners are faced with the lack of a framework for the problem of the brand identity creation.

\section{The brand identity development algorithm}

Summarizing the approaches of various branding scholars, it can be concluded that the brand identity:

- $\quad$ is a strategic concept of the brand, an external expression, a set of its identifiers;

- $\quad$ reflects the unique characteristics of the brand that motivate the buyer;

- $\quad$ plays a major role in the process of the brand recognition and forms its uniqueness;

- $\quad$ is the element that forms the model and brand image.

Thus, it can be concluded that the brand identity as a system of its distinctive feature is the main concept in the brand management.

The foundation of brand's distinctive feature system development is the common brand strategy which in turn should be harmoniously combined with the corporate and business strategies. The activity of the brand's identity creation can be divided into two main stages: the first - fits into the concept of strategic marketing and implies the determination of significant differences between the brand and the competitive brands; correctly selected comparisons that allow consumers to distinguish the brand from the general range; positioning the brand and shaping its concept. In the second stage, the identity itself is being developed as the way of how the customers should perceive the brand according to the brand developer's plan.

For a system of brand characteristics development the authors propose the algorithm which is presented on the figure.

So, first of all it is necessary to analyze the current market situation, particularly to formulate answers to the following questions:

-What is the current position of the company?

-Where does it want to be?

-What should be done to get there?

-What can prevent it?

In order to understand the current position of the company, it is necessary to analyze the factors of its macro- and microenvironment.

The next step is the examination of the company's economic conditions and activities.

Based on the analysis of marketing activities and the marketing concept that is followed by the firm, marketing strategies should be defined and scrutinized.

During the implementation of these steps, the product should be compared to the products of competitors and substitute goods. Particular attention should be paid to the process of segmentation and understanding of which segments the company's consumers belong to (in particular, according to geographic, demographic, psychographic, behavioral variables), as well as the features of the buying center members. 


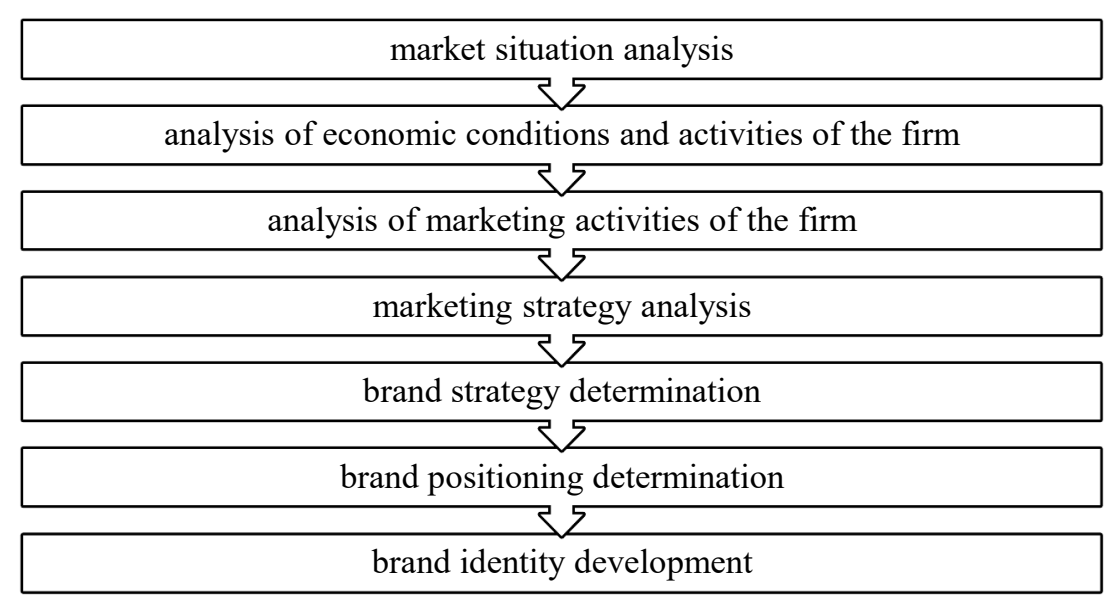

Fig. 1 The brand identity development algorithm.

Based on the analysis, we should move to the stage of the brand platform creation, specifically, to the positioning strategy development, including the formation of a unique selling proposition. If the positioning strategy is defined, we can move on to the brand identity creation.

There are several models of identity, each of which includes different characteristics. The most famous are: Brand Identity System (D.A. Aaker, USA), Brand Identity Prism (Jean-Noel Kapferer, France), Chernatony Brand Identity Model (L. De Chernatony, United Kingdom), 4D Branding (T. Gad, Sweden), Brand Wheel (Bates Worldwide, USA), Brand Platform (Young and Rubicam, USA). Analyzing these models, it can be noted that in the process of identity development and the choice of the brand's attributes it is necessary and sufficient to comply with the conditions, such as: uniqueness (the presence of the unique feature that allows the brand to stand out among the others); non-copyability (complex, resource-intensive copying possibility); leadership (necessity to be the first, the best in some area); controllability (the key attributes should be controllable); demand (the brand attributes really need to be demanded by the consumer).

\section{Developing brand identity in the business-to-business (B2B) markets}

When developing the brand identity, you need to take into account the market in which the organization operates. The company can work in the consumer market, in the B2B market, as well as serve the interests of both corporate and individual consumers. Thus, the identity of an industrial brand should be based on those characteristics that are key for corporate clients.

To form an identity model adapted to B2B markets, it is essential to reveal its main differences in comparison with $\mathrm{B} 2 \mathrm{C}$ market and to consider its important features.

B2B market is extremely complicated and complex. The total value of sales is usually higher in the $\mathrm{B} 2 \mathrm{~B}$ in comparison with $\mathrm{B} 2 \mathrm{C}$ where it can vary greatly. Purchase process in the $\mathrm{B} 2 \mathrm{~B}$ market usually requires more time and demands a lot of attention than in the $\mathrm{B} 2 \mathrm{C}$ market. The business customers are well-informed about alternatives and have the tendency to make balance decisions which is based on cold business calculation. So, the emotional aspect of purchase is of less importance.

However, the use of branding for business organizations has its benefits which is hard to underestimate. There are the positive image and reputation of the company as a reliable 
partner allows it to sell other types of products to the same buyer; the brand-guaranteed quality of goods and services motivates the buyers to the repeated purchases; developed brands of components add value to the final product and serve as key factor in making purchasing decisions by business clients.

Another argument in favor of brand development in B2B markets is the inertia of business buyers, who are not inclined to experiment. In both cases as in the B2B, as well as B2C markets the brand serves as a guarantee of stable quality. Both the individual and the business consumers tend to give preference to well-known brands, individuals - because they buy for themselves and do not want to experience disappointment after, the members of DMU are responsible for the purchase to the top management and their choices should be justified, reasonable and substantiated.

Organizations which operate in B2B market work on the relationship-driven selling environments. Developed brand identity can serve as an essential element that helps to form the strong brands and the relationships and interaction with a client should be reflected in the brand identity model.

Analysis of the Jean-Noel Kapferer's Brand Identity Prism allows us to conclude that it reflects all the key groups of brand identity attributes important to the individual consumer. D. Coleman and L. De Chernatoni's rightfully suggested that in the brand identity model for B2B enterprises, the interaction between the consumer and the company should play a special role.

Recent studies consider forming the brand identity as the process of its "co-creation." It is noted that building brand identity is the result of the interaction of numerous stakeholders [10-14].

This understanding has affected all groups of brand characteristics reflected in their model. We believe that when combining models in the process of identity formation, it is possible to take into account the characteristics of both corporate and individual consumers.

The conceptual Brand Identity Model for B2B markets is presented in the picture.

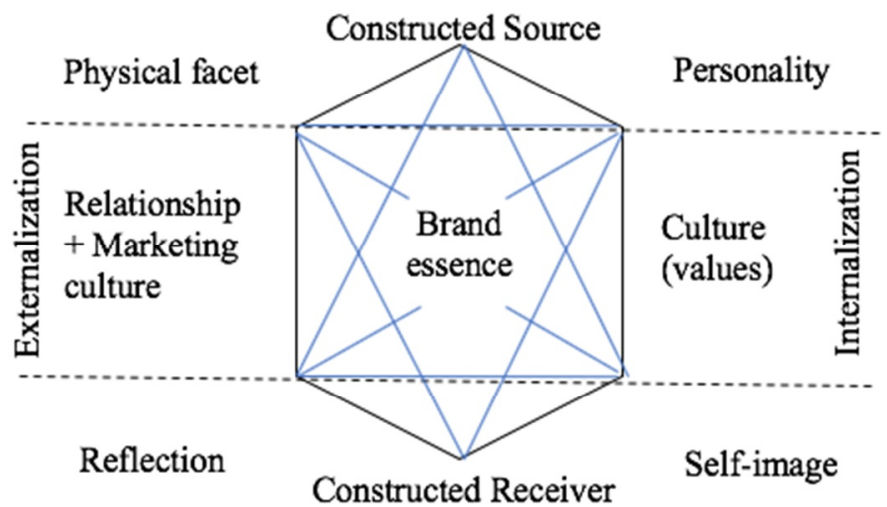

Fig. 2. Brand Identity Model for B2B markets.

It has two key features that distinguish it from the J.-N. Kapferer's Brand Identity Prism, namely, displaying all elements of identity as a network, which emphasizes the continuous nature of the relationship between the elements, as well as the presence of an element of "marketing culture" that can be both an additional facet of the polyhedron and a part of the "relationship" category.

It should be noted that when using this model, brand managers need to take into account the fact that business consumers and individual consumers perceive the brand 
characteristics (facet) in a slightly different way. Therefore, further we consider the elements of the facets in its application for both segments.

\subsection{Physical facet}

Physical facet refers to both the physical attributes of assortment units and the unity of physical characteristics of the entire brand in its integrity. In order to gain an additional competitive advantage and prolong the life cycle of the product, it is possible to use sensory branding tools, developing the system of attributes in such a way as to use the optimal, relevant for the consumer combination of the visuals, auditory, tactile and taste characteristics taking into account previous medialized experience of the end user which often has

For the most accurate contact with the consumer, you need to make a map of customers' touchpoints. To develop a brand in the B2B market it is essential to analyze carefully the contacts with the members of the decision-making unit (DMU) and find out the behavioral characteristics of each of them.

\subsection{Individuality}

Individuality is the description of the brand characteristics in the categories of personality traits. From the psychological point of view, the product in this case becomes a tool of selfidentification of the consumer by projecting on him their own desires, experiences, preferences. It can be a celebrity personifying the brand, a company manager, a fictional character, an advertising hero or a steady set of associations. This component of identity reflects the promise of the brand, which in the future must be confirmed and, in an ideal situation, should coincide with consumer expectations. D. Aaker cites five main types of brand identity: sincerity, excitement, competence, sophistication and turbulence [15].

V. N. Domnin believes that the individuality of a brand can be described by the types of relationships prevailing between the buyer and the brand. He divides them into "value", "sensual" and "characteristic". If relationships based on assessment and knowledge dominate, the concept of values becomes a key category. From the global market prospective it is essential to address the key values of target audiences around the world. If consumers are looking for strong feelings and experiences, the category of "sensuality" prevails. Most brands today are focused on joyful emotions, which does not allow to create a difference in this aspect. You can use the "characteristic" category to describe the active, behavioral component of the brand identity [6].

\subsection{Culture}

This aspect, as well as the individuality of the brand, refers to the meaningful features of the brand. It can reflect the image of the country of origin, the history of the company or the product, the traditions, and the corporate values (J.-N. Kapferer), national features, etc. In particular, K.P. Zeugner-Roth, H. van Herk, C. Torelli claim that even perceived origin of the product affects the customer behavior therefore it should be a point of focus in the management of brands [16]. Besides the all mentioned, the individual medialized experience of the end user, which often has an affective or emotional interaction with the product, which can not always be rationally expressed, should be taken into account. [17] 


\subsection{Relationship}

Relationship refers to a specific type of interaction between the consumer and the brand, a type of behavior that mostly identifies brands. The facet of relationships determines the way of the brands' performance, the services' delivery, the nature of relationships with consumers. In defining this group of characteristics, we can consider the archetypes of consumer behavior in our product category, but bearing in mind the complex structure of the decision-making unit (DMU), we must take into account, first, the entire system of relationships with each member of this unit, and secondly, their behavioral features. Therefore, we have added the "marketing culture" element to the Brand Identity Model for B2B markets presented above.

\subsection{Reflection}

Reflection refers to how the consumer would like to be perceived by others and what impression they would like to make when using the brand. In this case, the brand acts as a means of establishing relationships, integrating with the group, or achieving collective goals. In terms of B2B brands, this facet may have a hue of professionalism and status.

\subsection{Self-image}

The brand acts as a means of self-identification. As for B2B brands, like in the case of reflection facet, self-image can have a tinge of professionalism, status, modernity, and conservatism.

\subsection{The brand essence}

The brand essence can be stated with a couple of words and reflects the group of intrinsic traits of the brand that determine what the company stands for, its core mission and idea.

\section{Conclusions}

1. The article explores the concept of "brand identity" as a central element of brand, planned brand image, defining the direction for all marketing activities of the company. It is concluded that the identity of the brand is a strategic concept of the brand, its external expression, and the set of its identifiers. The identity reflects the unique characteristics for the brand, motivating the buyer; plays a major role in the process of the brand recognition and shapes its uniqueness; is the element that forms the model and image of the brand.

2.To build the brand strategy characteristic features system an algorithm has been developed which includes market situation analysis, analysis of economic conditions and activities of the firm, analysis of marketing activities of the firm, marketing strategy analysis, brand strategy determination, brand positioning determination, and brand identity development stages.

3.The analysis of the B2B market features has been carried out which showed the differences B2B market in comparison with the B2C market and allow to find out their common traits, based on which the identity model should be developed.

4.The authors examined the models such as The Brand Identity System (DA Aaker, USA), The Brand Identity Prism (Kapferer J.-N., France), L. De Chernatoni's model (UK), 4D Branding (T. Gad, Sweden), The Brand Wheel (Bates Worldwide, USA), The Brand 
Platform (Young \& Rubicam, USA) and formed the brand identity model adapted to the B2B market.

5.Based on the examinations the conceptual approach to the brand identity development is proposed which takes into account the interests of individual and business customers and allows the firm to serve both markets. Its distinguish features are the combination of all the identity elements in a network, which emphasizes the continuous nature of the relationship between them, and the addition of an element "marketing culture" that can be both an additional facet of the polyhedron and a part of the "relationship" category.

\section{References}

1. M. B. Yanenko, Teoretical foundations of formation and evaluation of brand capital: monograph, (POLITEH-PRESS, Saint-Petersburg, 2019). doi:10.18720/SPBPU/2/19-204

2. S. Fournier, M. Breazeale, J. Avery, Strong Brands, Strong Relationships (Routledge, London, 2015). doi:10.4324/9781315767079

3.C. Viot, J. of Pr. \& Br. Manag., 20, 216-227 (2011). doi: 10.1108/10610421111134941

4. M. Urde, J. Brand. Manag., 20, 742-761 (2013). doi:10.1057/bm.2013.12

5. R. R. Gehani, J. Technol. Manag. Innov., 11(3), 11-20 (2016). doi:10.4067/S071827242016000300002

6. V. N. Domnin, S.A. Starov, Vestn. Saint. Petersbg. Univ. Manag., 16(1), 5-32 (2017) doi:10.21638/11701/spbu08.2017.101

7. C. Burmann, N.-M. Riley, T. Halaszovich, et al., Strategic Brand Management. In: Identity-Based Brand Management (Springer Gabler; Wiesbaden, 2017). doi:10.1007/978-3-658-13561-4_3

8. P. Kotler, W. Pförtsc, Basics of Ingredient Branding, (Springer, Berlin, Heidelberg 2010). doi:10.1007/978-3-642-04214-0_2

9. E. Kostelijk, K. Alsem Brand Positioning, (Routledge, London, 2020). doi:10.4324/9780429285820

10. S. Mindrut, A. Manolica, C.T. Roman, Procedia Econ. Financ., 20, 393-403 (2015). doi:10.1016/S2212-5671(15)00088-X

11. M. Törmälä, R. I. Gyrd-Jones, Ind Mark Manag., 65, 76-85 (2017). doi:10.1016/J.INDMARMAN.2017.05.002

12. O. Iglesias, P. Landgraf, N. Ind, S. Markovic, N. Koporcic. Ind. Mark. Manag., (2019). doi:10.1016/j.indmarman.2019.09.008

13. A. Essamri, S. McKechnie, H. Winklhofer, J. Bus. Res., 96, 366-375 (2019). doi:10.1016/J.JBUSRES.2018.07.015

14. S.Wallpach, B. Voyer, Benjamin, M. Kastanakis, H. Mühlbacher, J. Bus. Res, 70, 395-398, (2017). doi:70. 10.1016/j.jbusres.2016.08.028

15. S. Okazaki, Int Mark Rev., 23, 279-303, (2006). doi:10.1108/02651330610670451

16. K.P. Zeugner-Roth, H. van Herk, C. Torelli, Country-of-Origin Effects. Cross Cultural Issues in Consumer Science and Consumer Psychology (Springer, Cham, 2017). doi:10.1007/978-3-319-65091-3_7

17. M.A. Stepanov, Int. J. of Cult. Res. 3(36), 231-235, (2019). DOI: 10.24411/20791100-2019-00046 